\title{
REFLEXIÓN SOBRE EL CINE DE VISCONTI DESDE EL ESTUDIO DE SU NARRATIVA AUDIOVISUAL
}

\section{REFLECTION ON VISCONTI FILM FROM THE STUDY OF HIS AUDIOVISUAL NARRATIVE}

\section{AUTOR}

Alfonso Ricardo Felipe López

Universidad San Pablo CEU. Madrid (España)

alfonso.rfl@gmail.com

\section{RESUMEN}

Este artículo pretende reflexionar sobre la narrativa audiovisual de Luchino Visconti di Modrone (Milán, 1906 - Roma, 1976). Aristócrata, director teatral y después, director de cine, rodó más de veinte películas justo hasta el año de su muerte. Entre su obra destacan los títulos: Obsesión, La tierra tiembla, Senso, Rocco y sus hermanos, Boccaccio 70, El gatopardo, Las brujas, El extranjero, La caída de los dioses, Muerte en Venecia, Luis // de Baviera, Confidencias o El inocente. Su gusto estético, onírico y por supuesto, teatral, ha hecho que sus películas se conviertan, individualmente, en auténticos ejemplos de todo lo que se estudia en materia de narrativa audiovisual. Este artículo pretende desentrañar sus características desde la mirada de un joven que empieza a formarse como realizador.

\section{PALABRAS CLAVE}

Visconti - Narrativa audiovisual - Realismo italiano. 


\section{ABSTRACT}

This article aims to reflect on the visual narrative of Luchino Visconti di Modrone (Milan, 1906 - Rome, 1976). Aristocrat, theatre director and then, film director, shot just over twenty films until his death. Among his work are the titles: Obsesión, La tierra tiembla, Senso, Rocco y sus hermanos, Boccaccio 70, El gatopardo, Las brujas, El extranjero, La caída de los dioses, Muerte en Venecia, Luis // de Baviera, Confidencias o El inocente. His aesthetic, dream and of course, theatrical taste, has made his films become, individually, real examples of what is learned in the field of audiovisual narrative. This article tries to unravel its characteristics from the perspective of a young student who begins to form as a filmmaker.

\section{KEY WORDS}

Visconti - Audiovisual narrative - Italian realism.

\section{ÍNDICE}

1. Los temas de Visconti.

2. Planos, encuadres, profundidad de campo.

3. Planificación, montaje y sentido del ritmo.

4. Recursos temporales: elipsis, flashback, flashforward.

5. Iluminación, tono y color.

6. Dirección artística.

7. Valoración personal.

8. Bibliografía. 


\section{Los temas de Visconti}

La decadencia es el tema principal en todo el cine de Visconti. Al ver cada una de sus películas el espectador tiene la sensación de ver una gráfica descendente que representa a los protagonistas de la obra. Decadencia en los personajes, en las situaciones, en el ambiente... Todo se torna cada vez más oscuro a medida que pasan los minutos de la cinta. Es algo que se puede percibir en todas las películas del realizador:

- En Rocco y sus hermanos, la familia del protagonista se descompone a raíz de su llegada del campo a la ciudad. El ejemplo más claro lo representan los hermanos Rocco y Simón, quedando ambos sumidos en la desesperación por culpa de su amor por Nadia.

- En El gatopardo, observamos la decadencia de la clase aristocrática (representada en la figura de D. Frabrizio de Salina) y su sustitución por una clase nueva (representada por el padre de Angélica, el campesino Sedara).

- La caída de los dioses es la crónica del derrumbe de una poderosa familia alemana dueña de una gran empresa de fundición.

- En Muerte en Venecia vemos cómo Gustav Aschenbach se ve superado por su amor a la belleza de Tadzio y entra en un proceso autodestructivo, que termina con su fallecimiento en la playa.

- El viejo profesor de Confidencias observa la pérdida de su recién adquirida familia, y al mismo tiempo es consciente de que el paso del tiempo acabará por hacerle morir sin tener a nadie a su lado. La vida del personaje de Konrad es otro ejemplo de la decadencia que el realizador ofrece en sus películas (el personaje recuerda con nostalgia su vida anterior).

- El fin del amor de la pareja protagonista de El inocente lleva a una serie de desdichas que finalizarán con el suicidio del protagonista. 
Otro de los temas presentes en las películas del director italiano es la Aristocracia. La figura del noble es algo típico en el cine viscontiano (tal vez debido a que el propio Visconti era noble). Los palacios y la recreación de la vida dentro de ellos es algo que aparece en todas sus películas, muchas veces como punto de partida para acabar mostrando la imagen marchita del mundo aristócrata: sus bailes, su belleza, su barroquismo deja paso a la perversión, la corruptibilidad y la degeneración. Es un tema que se encuentra muchas veces unido al anterior, complementándose y al mismo tiempo ofreciendo un contraste al espectador del antiguo poder y la situación actual.

- El ejemplo más claro lo representa El gatopardo. Es la película donde mejor se ve el contraste entre el lujo y el fin de la vieja nobleza. La película recrea los grandes palacios como Donnafugata, casas en las que uno puede perderse y en las que es imposible conocer todas las salas (mostrado perfectamente en las escapadas amorosas de Alfonso y Angélica), los bailes y las fiestas, los valses y las mazurcas, los criados y los trajes.

- La caída de los dioses es la decadencia de la familia von Essenbeck, una familia noble que antes de su ocaso (y de alguna manera también después de ésta) vivía de manera fastuosa, rodeada por el lujo. La escena de la cena de celebración del cumpleaños de Joaquín, patriarca del clan, es la mejor muestra del esplendor aristocrático.

- Gustar Aschenbach y la familia de Tadzio pertenecen a la aristocracia. El modo de vida burgués se contempla perfectamente en las escenas de playa que aparecen a lo largo de la película y también, en las que transcurren dentro del hotel, sobre todo en la del primer encuentro de Gustav y Tadzio.

- Los molestos inquilinos de Confidencias representan el espíritu snob y burgués. Visconti no sólo lo muestra, sino que lo pone en contraposición con el socialismo y los movimientos obreros en una de las últimas conversaciones que se producen al final de la película.

- El lujo que rodea a los personajes de El inocente, también de origen noble. 
La figura materna es mostrada de mil maneras a lo largo de la obra de Visconti (debido al recuerdo de su propia madre, Carla Erba, una de las personas que más marcó la existencia del director). Es un personaje (el de la madre) que siempre rebosa fuerza y tiene un papel importante en la historia, siendo retratado de las maneras más diversas:

- Una figura buena y protectora, ocupada de guardar de la unidad familiar y de cuidar de sus hijos en Rocco y sus hermanos.

- Un guiño sórdido e incestuoso en La caída de los dioses, dónde Sofía es una madre manipuladora que lleva a su hijo a la locura.

- La madre de Tadzio en Muerte en Venecia ofrece un claro paralelismo con el recuerdo de madre buena y elegante que guarda Visconti de la suya propia. Es madre y aristócrata recogiendo los rasgos buenos de los dos términos (sin la imagen decadente 0 sórdida del cine viscontiano).

- La figura materna es el nexo de unión entre todos los personajes en Confidencias. Es la figura de madre aristócrata, al igual que la madre de Tadzio, pero la que aparece aquí sería la imagen sórdida burguesa.

- La madre que ama a su hijo y que lo trata de proteger a toda costa aparece en $E$ I inocente. Es una figura materna atormentada y que acaba sumida en la desesperación al ver la muerte de su bebé.

La sexualidad es otro de los temas tratados con frecuencia. Los impulsos invaden a los personajes y éstos se dejan llevar por deseos ocultos y por pasiones que les arrastran a su propia perdición. Es frecuente encontrar toda clase de perversiones en el cine de Visconti y situaciones límite que tienen su origen en el deseo sexual:

- La disputa por el amor de Nadia entre Simón y Rocco será el factor que acelere la desintegración familiar. La escena más dura se produce cuando Simón viola a Nadia ante los ojos de su hermano, por los celos que siente al no ser él el elegido por la chica. Desde ese punto, vemos que la 
desesperación de los protagonistas crece hasta acabar en el asesinato de Nadia a manos de Simón y la entrega de éste a la policía por Ciro.

- El deseo y la seducción están presentes en todas las escenas en que Alfonso y Angélica se encuentran juntos en El gatopardo. El deseo se ve refrenado en esta cinta y se limita a juegos entre los dos enamorados. En unas escenas censuradas, se veían unos sueños de carácter sexual que tenía el Príncipe de Salina en la noche que paran a descansar de camino a Donnafugata.

- La caída de los dioses se encuentra llena de referentes sexuales. Todos muestran una imagen sórdida que resalta el salvajismo y la crueldad en la que se encontraba sumida Alemania en aquella época. El centro de la mayor parte de las perversiones sexuales se encuentra en Martin. Es un personaje atormentado que encuentra fascinación en las niñas pequeñas (llegando al estupro con una y provocando su muerte), travestido y que acaba por cometer incesto con su madre. También se ofrece una imagen salvaje de las SA que se mezcla con la homosexualidad.

- Muerte en Venecia muestra deseo y amor del protagonista por Tadzio. No se llega a dejar claro del todo la homosexualidad y la pederastia de Aschenbach, que también puede ser interpretado como un amor hacia lo bello. A pesar de todo, el personaje de Tadzio es uno de los más complejos de analizar en este aspecto, ya que es contradictorio. Por un lado, simboliza el amor y el ideal de belleza de Gustav, y entra en el juego de éste tentándole con miradas que están cargadas de malicia. Por otro, vemos cómo el personaje reacciona de mala manera a todas las insinuaciones que se le presentan: el músico que le canta versos impúdicos y los juegos que realiza con Jaschou, al que siempre acaba echando enfadado.

- El profesor descubre in fraganti a Konrad, Stefano y Lietta, desnudos en su salón realizando juegos sexuales en Confidencias. Se deja entrever ligeramente el tema del incesto, ya que Konrad es el amante de la madre de Lietta. 
- El juego de parejas y las infidelidades de Tulio a Julia desencadenan el trágico desenlace de la obra.

Una figura que aparece en muchas de las películas de Visconti es la de un niño:

- En Rocco y sus hermanos era el encargado de devolver la esperanza a la familia y dejar una pequeña puerta abierta de cara al futuro.

- Son los protagonistas de la obsesión de Martin en La caída de los dioses. La niña hebrea que se ahorca o sus dos primas pequeñas. Todos los niños que aparecen en esta película mueren, son los más inocentes de todos los personajes que salen en la trama y por eso no podían sobrevivir. Los demás personajes no tenían ningún tipo de escrúpulo en hacer el mal. Y eso lo plantea Visconti como requisito para seguir vivo en la Alemania nazi.

- Tadzio encarna la belleza. Es el ángel de la muerte que lleva a Aschenbach a su destrucción.

- El inocente muestra la figura del bebé que muere por culpa de los pecados de sus padres.

La familia es otro de los temas que más obsesionan a Visconti: en Rocco y sus hermanos relata la crisis de la sociedad italiana a través de los ojos de una familia; en El gatopardo la estructura social de Italia cambia y es visto desde el interior de la familia Salina; en La caída de los dioses el ascenso del nazismo es contemplado por los miembros de la familia Essenbech. En Visconti, la familia es el sitio donde se reflejan los acontecimientos del mundo.

La literatura es una de las mayores influencias del realizador a la hora de llevar a cabo una película, no sólo en el hecho de adaptar una novela o relato al cine (de las seis películas que he visto cinco son adaptaciones), sino en los rasgos de su cine. Lo que cuenta Visconti remite a lo que escribieron Proust, Mann y Joyce. Hay varios temas que comparte con dos de sus escritores favoritos: Marcel Proust y Thomas 
Mann. El gusto por lo bello, el paso del tiempo, la muerte, la soledad. Todos estos temas tienen cabida en sus películas.

El amor de Visconti por la belleza podría compararse al que siente Aschenbach por el arte y lo bello. Pero también es comparable con el amor que siente su profesor de Confidencias por los cuadros y la literatura. 0 la fascinación que llegan a ejercer la simbología nazi desplegada buscando lo puramente estético en La caída de los dioses. 0 todo el barroquismo desplegado en cada película. Son todos ejemplos de la atracción del director italiano por el arte y por lo netamente bello. Los otros tres temas están muy relacionados entre sí. El paso del tiempo, la muerte y la soledad se reflejan perfectamente en El gatopardo, Confidencias, Muerte en Venecia y La caída de los dioses. D. Frabrizio, nostálgico tras bailar en la fiesta y añorando la juventud de su sobrino Alfonso, la cita de la Biblia sobre la soledad llevada a cabo por Konrad, los continuos recuerdos de Gustav sobre su pasado o el cambio de jefe dentro del clan Essenbeck.

Se deja ver en Visconti una fascinación por el sur de Italia. Es un tema presente en Rocco y sus hermanos y en El gatopardo. Los protagonistas de la primera película tuvieron que irse de su pueblo a la ciudad en busca de la fortuna que no podían conseguir en el campo. En el segundo relato la familia Salina acude a una villa que tienen en el sur de la península itálica.

El autor muestra una visión desesperanzada de la sociedad. Una desesperanza que alcanza a todas las clases sociales, desde las más bajas (Rocco y sus hermanos) a las más elevadas (familia Salina)

El cine de Visconti es decadente, los personajes siempre se mueven de más a menos, son seres atormentados que viven una situación de cambio en sus vidas y que les empuja a su propio fin. Otros temas frecuentes en su cine son: la aristocracia, la figura materna, la figura infantil, la belleza y el arte, la literatura, la 
fascinación que causa el poder y las clases privilegiadas. Lo sexual también está muy presente en el cine viscontiano. La muerte, la soledad y el paso del tiempo son otros de los temas que el realizador tiene presente en sus obras. El sur de Italia es otro aspecto que causa la fascinación de Visconti.

\section{Planos, encuadres, profundidad de campo}

Visconti es un director al que le gusta mover la cámara, pero nunca lo hace de un modo caprichoso. Siempre que un encuadre se mueva dentro de una obra del realizador italiano es por una razón: la aparición de un nuevo personaje, el recalco de la acción de uno de los que está en ese momento en pantalla, la preparación del plano para encadenarlo con el siguiente,... siempre utiliza dos tipos de movimientos: los paneos y los zooms.

Mediante el uso de estos movimientos el director realiza varias acciones:

- Reencuadrar a los personajes principales: la acción dramática hace que el personaje se mueva y salga del cuadro. Visconti sigue siempre a sus personajes. Hay decenas de ejemplos en las seis películas vistas: los paseos de Aschenbach en Muerte en Venecia, el paso firme del Príncipe de Salina en El gatopardo, la familia de Rocco avanzando por la estación, los diálogos de Tulio mientras camina por la habitación en El inocente, la llegada a la casa de los Essenbeck de Frederic y Aschenbach en La caída de los dioses o la visita de Konrad al despacho del profesor en Confidencias.

- Describir un paisaje o lugar: Visconti hace que la cámara abandone a su protagonista y se mueva libremente a lo largo de todo el decorado, deleitando al espectador con cada detalle y resaltando ciertas partes del escenario recurriendo a los zooms. El ejemplo más claro aparece en Muerte en Venecia. La cámara realiza un recorrido completo por la sala de reuniones del hotel y muestra el ambiente que allí se respira, antes de que la cena esté preparada 
(la escena de la audición de El inocente y la de la cena al comienzo de La caída de los dioses son calcadas a ésta). En Muerte en Venecia, la función descriptiva de los movimientos de cámara está más remarcada que en otras de las películas de Visconti: en la muestra de las calles venecianas, las escenas en la playa o en el hotel. Al director italiano le gusta usar la descripción para introducir uno de los temas citados más arriba: el de la burguesía. La visión del lujo mediante movimientos de cámara hace que los espectadores se introduzcan en la magnificencia burguesa transmitiéndoles la sensación de estar dando una vuelta dentro de los salones.

- Resaltar un personaje secundario: muchas veces existen personajes que se encuentran en el fondo del cuadro y en los que el espectador no había reparado, bien porque acaban de entrar en el cuadro o bien porque la atención del público se centraba en otro lado del encuadre. Al principio, parece que el movimiento de cámara no tiene sentido. Pero tras unos segundos, reparamos en ese personaje cuya aportación a la historia será breve y puntual. El camarero que anuncia la cena en Muerte en Venecia es un ejemplo de esto.

- El zoom es uno de los recursos más usado por el realizador italiano. Es una constante en todas sus películas, el director hace que el espectador se acerque a la acción como si se acercara a un cuadro: el tamaño de los objetos entre ellos permanece proporcional, lo único que cambia es que el tamaño de la imagen es mayor. Un recurso generalmente feo es usado con gran maestría por Visconti y permite observar su obra como se observa una pintura y dotándola de la misma belleza. Es un recurso que, por otro lado, el italiano asocia a las emociones de los personajes; es muy frecuente ver ampliarse la imagen cuando un discurso de uno de los protagonistas cobra más fuerza y alejarse cuando éste empieza a declinar, o que se pase a un primer plano cuando la tensión dramática aumente. 
El tamaño de los encuadres está muy cuidado en todas sus películas. Siempre combina los planos largos y los cortos y los combina mediante el uso del zoom y su talento en el montaje, gracias a eso puede pasar de situaciones descriptivas a otras más dramáticas y hacer que ambos conceptos lleguen muchas veces a mezclarse. Por ejemplo, los planos cortos de Aschenbach en el arranque de Muerte en Venecia son dramáticos en el sentido que ayudan a ver el estado de ánimo del personaje pero, al mismo tiempo, consiguen apoyar la descripción del paisaje. Es destacable el conocimiento que demuestra el autor a la hora de transmitir sensaciones a los espectadores simplemente variando el tamaño del plano: para mostrar agobio encajona las cabezas de sus personajes en los planos cortos, por ejemplo en la escena final de El inocente (cuando Julia le dice a Tulio que le desprecia) o las escenas finales de Muerte en Venecia (cuando Aschenbach está en la playa y el tinte se empieza a derretir o los planos en que el protagonista se encuentra en el interior de un ascensor lleno de niños). El encajonamiento de los planos suele producirse siempre en los últimos momentos de sus películas, cuando el recorrido hacia la decadencia casi se ha completado.

Otro elemento narrativo perfectamente usado es el de la profundidad de campo. El desenfoque dentro del cuadro hace que la atención del espectador se dirija al punto exacto de cada imagen. Es un rasgo muy importante, debido al barroquismo que impregna la obra de Visconti y que podría hacer que el público se distrajese de la acción principal por culpa de lo recargado que está el fondo. Es un elemento básico en los ambientes burgueses de El inocente, La caída de los dioses, El gatopardo y Muerte en Venecia.

Los abundantes movimientos de cámara del cine de Visconti (paneos y zooms) se ocupan de los siguientes objetivos: reencuadrar a los personajes principales, describir un ambiente o lugar y resaltar un personaje que de otro modo habría pasado inadvertido al espectador. El uso del zoom aporta además dos cosas: el ampliar la imagen de la misma manera que un amante del arte observaría un cuadro 
(la razón estética) y el permitir acercarse a los personajes o alejarse de ellos de acuerdo con su nivel emocional. El tamaño de los encuadres le permite hacer sentir al público sensación de agobio encajonado a los personajes dentro del plano (sacarles cortados en el encuadre). El uso de la profundidad de campo le permite centrar la atención del espectador dentro de la imagen.

\section{Planificación, montaje y sentido del ritmo}

La manía de Visconti por pulir hasta el último detalle y su obsesión por alcanzar la perfección, se dejan ver en la planificación de todas sus películas. Es algo que se nota en los detalles más sutiles. Hay un ejemplo de Muerte en Venecia, cuando el protagonista acaba de llegar a tierra traído por un gondolero y se aleja un momento del muelle. Nada más alejarse, se ve en plano general a una pareja de policías que se cruzan con él en sentido contrario. En la siguiente escena, vemos cómo los dos policías hacen huir al gondolero (no tenía licencia). Todo tiene que estar en su sitio y funciona en escena como la maquinaria de un preciso reloj. Dentro de la planificación, cabe destacar dos aspectos: el fuera de campo y el uso de los espejos para completar la narración. En el fuera de campo, brilla el uso que el director hace de las miradas de los personajes. Dirk Bogarde, haciendo el papel del músico Gustav Aschenbach, es un buen ejemplo. La línea marcada por sus ojos nos permite imaginar qué está mirando.

Los espejos en el cine viscontiano son un elemento más puesto al servicio del director para superar las limitaciones del encuadre. Es uno de los rasgos más preciosistas de la obra del director italiano. Mediante un detallado trabajo de planificación del cuadro, el director ofrece en un mismo plano dos imágenes incompatibles. También es un recurso que emplea para poder realizar virguerías estéticas a la hora de mover la cámara: 
- En La caída de los dioses vemos cómo la cámara enfoca a Constantino por detrás en plano general y el zoom no se acerca a é,l sino a su reflejo en el espejo en plano corto. Sin necesidad de cambiar de plantel realizador, nos muestra la expresión del actor.

- En El gatopardo, los planos-contraplanos de Alain Delon y Burt Lancaster se realizan mediante un juego de espejos que siempre nos permite ver a los dos personajes de frente.

- En Muerte en Venecia, vemos al protagonista arreglándose antes de la cena y nos es mostrado desde varios puntos de vista. Será un espejo el que le muestre, al final de la película, en qué se ha convertido.

Esta planificación se apoya en un montaje de rasgos muy clásicos: nunca se salta un eje y cumple al milímetro la regla de los 90‥ La escena de Gustav observando las fotografías de su mujer y de su hija es un ejemplo perfecto de aplicación de la regla de los $90^{\circ}$. La cámara gira lo suficiente para que el espectador se oriente ante lo que está viendo y, al mismo tiempo, obtiene información nueva que no se encontraba dentro del encuadre. El paso de un plano a otro se produce siempre al corte, nunca por encadenado. Ni cuando recurre al uso de recursos temporales (que serán vistos más abajo), el autor opta por emplear encadenados.

El ritmo del cine de Visconti está fundamentado en el montaje y la planificación. Es un cine lento pero no aburrido. El director se toma tiempo para que el espectador reflexione sobre los temas expuestos. En algunas películas, acelera el pase de un plano a otro y realiza un montaje más picado; el principio de El inocente, por ejemplo. Luego recobra la calma y permite disfrutar al espectador de una historia pausada. Muerte en Venecia es la que más se regocija a la hora de mostrar planos lentos y largos, que permiten al espectador abstraerse a un mundo dónde sólo lo estético importa. El pasar del metraje de cada película recuerda a En busca del tiempo perdido de Proust. En El gatopardo, la decadencia de los Salina se presenta sin ningún tipo de prisa, simbolizando la propia sustitución de una clase por otra: con 
lentitud pero sin pausa. $Y$ es que así es el cine de Visconti. Las historias se desarrollan despacio, sin llegar a pararse. Disfrutando el camino que lleva hasta el final, aunque éste sea terrible.

\section{Recursos temporales: elipsis, flashback, flash-foward}

El director italiano es todo un experto a la hora de jugar con el tiempo. Pocos directores conocen mejor los trucos para hacer que un relato se prolongue, avance rápidamente, se detenga o retroceda. La película de toda la obra de Visconti que recoge los tres elementos es Muerte en Venecia. Aunque no es algo aislado de esa cinta; el uso de los recursos temporales se ve en todas las películas del realizador.

Las elipses permiten a Visconti adelantar y conseguir que el tiempo avance más rápidamente. Su habilidad le permite emplearlas en los momentos justos, sin cortar el ritmo de la película. Algunos ejemplos de elipses son:

- El periodo de tiempo desde la llegada de Rocco y su familia a la gran ciudad hasta el momento en que aparecen ya instalados en una casa.

- El continuo avanzar del tiempo en El gatopardo, que hace que se nos cuenten acontecimientos separados por varios años de diferencia.

- La escena del incesto de La caída de los dioses se pierde en una elipsis, sólo se nos muestran "los preparativos" y "el hecho". "El proceso" permanece en ese tiempo perdido descartado por Visconti.

- Muerte en Venecia ofrece numerosos ejemplos: el pase desde el desayuno al barco que habría de llevar al protagonista fuera de Venecia o la llegada al hotel desde el muelle son sólo una breve muestra.

El uso de los flashbacks y de los flashfowards marca la película de Muerte en Venecia. El autor pasa a ellos como pasaría a cualquier otra escena, al corte y sin dar ningún tipo de señal al espectador. Los flashbacks descubren aspectos del pasado de los personajes que Visconti inserta a placer dentro de la historia. En uno de ellos, 
aparece Aschenbach charlando con su amigo Alfred y el autor aprovecha para meter una reflexión acerca del tiempo. El flashfoward lo emplea de la misma manera y lo utiliza sin avisar al espectador en ningún momento: aviso a la madre de Tadzio de la epidemia de peste en Venecia.

Visconti utiliza las elipses, los flashback y los flashfowards de tal manera que puede modificar el tiempo de sus historias, sin que por ello el ritmo se vea afectado.

\section{Iluminación, tono y color}

El cine de Visconti juega mucho con los contrastes cromáticos y tonales. La iluminación de las escenas y el color de la imagen se ajustan a las emociones que el autor italiano quiere transmitir al público. La iluminación será suave cuando lo que ocurra dentro del cuadro sea un momento relajado, pero usará luces duras y fuertes sombras cuando haya momentos de más tensión. Un ejemplo de esa iluminación clásica y suave, sin ningún tipo de sombras y con luces de relleno que le dan a la pantalla un aspecto de pintura sería Muerte en Venecia. La luz en las grandes salas del hotel se corresponde con este tipo de iluminación uniforme, pero también lo hace la luz exterior cuando el personaje pasea por una Venecia desolada o cuando los personajes se encuentran en la playa. El inocente, Confidencias, La caída de los dioses y El gatopardo también ofrecen ese mismo estilo de iluminación. En Rocco y sus hermanos, rodada en blanco y negro, recurre a ese estilo clásico de tres puntos, utilizando la luz de contra para separar a los personajes del fondo.

Muchas veces, el director apela a la dramatización de los encuadres. Utiliza una luz dura que hace resaltar las sombras. En El gatopardo y en $E$ I inocente hay ejemplos de esta iluminación. Curiosamente, en ambas películas, la escena iluminada con una luz fuerte ocurre dentro de un carruaje. El interior del mismo es totalmente oscuro y sobre los rostros de los protagonistas se proyecta una fuerte luz. Otro ejemplo sería 
la escena del incesto en La caída de los dioses o cuando Burt Lancaster sube al piso de su inquilino utilizando una linterna, en Confidencias.

El uso del color y de los tonos aporta mucha vida a cada fotograma. Siempre emplea colores bastante chillones, aunque a veces los difumina un poco. En La caída de los dioses son colores saltones que a veces, dan un toque irreal al cuadro. En Muerte en Venecia, la luz y el color acaban por formar una visión onírica de la belleza: la composición de la playa con una barca en una de las esquinas, o la última visión que tiene Gustav de Tadzio antes de morir.

Visconti recurre a una iluminación clásica que, en ocasiones, llega al barroquismo para dotar de belleza a cada plano, recargarlo de color y de emoción. También recurre a dramatizaciones y contrastes de luces y sombras en algunas escenas.

\section{Dirección artística}

Al ser también director teatral, uno de los puntos fuertes del director es el aprovechar al máximo las capacidades de los actores. Eran como una especie de cascarones vacíos que el director se ocupaba de llenar. Era alguien capaz de crear mal ambiente en un rodaje para que la escena resultase más creíble. Su afán por llegar a la perfección le hacía dirigir cada gesto de los actores, como declaró Renaud Verley (el actor que encarna al personaje de "Gunter") en el DVD de extras de La caída de los dioses.

Una de sus características es que ya tenía una serie de actores fetiches que aparecen en varios de sus películas:

- Alain Delon: que protagoniza Rocco y sus hermanos y El gatopardo.

- Burt Lancaster: protagonista de El gatopardo y Confidencias.

- Claudia Cardinale: aparece en Rocco y sus hermanos y en El gatopardo. 
- Dirk Bogarde: protagonista de La caída de los dioses y Muerte en Venecia.

- Helmut Berger: protagonista de La caída de los dioses y Confidencias.

- Humberto Orsini: actor que usó frecuentemente en teatro y en La caída de los dioses.

Era un director capaz de hacer que un actor ofreciera lo mejor de si mismo. Su experiencia en el teatro le permitió ponerse en la piel de los actores e indicarles cómo quería que fuera su interpretación. Su espíritu perfeccionista hace que cuide hasta el más mínimo gesto que realiza uno de los protagonistas. Suele contar siempre con actores que ya conoce.

\section{Valoración personal}

El cine de Luchino Visconti requiere de un esfuerzo por parte del espectador para poder ser disfrutado. Al principio, no podía ver entera Muerte en Venecia y tuve que hacer varios intentos. Es un autor que propone un ritmo, sobre todo en esa película, muy pausado y lento, al que hay que acostumbrarse. Una vez que te adaptas a la velocidad de la película, al estilo pausado y relajado de cada plano y te paras a observar los decorados y los paisajes, el encanto de todos los detalles, el brillo de cada color y la belleza de la composición es cuando se descubre el cine de Visconti. Poco a poco, llaman la atención los pequeños detalles: un ligero movimiento de cámara que acompaña a un camarero en el fondo de la imagen, un arranque suave que relaja al espectador que lo contempla, reflexiones de los protagonistas sobre cuestiones abstractas... El cine de Visconti equivale a la contemplación de un cuadro en el que el pintor a cuidado cada detalle.

Tras el visionado de Muerte en Venecia, las demás películas fueron más fáciles de asimilar. El gatopardo me habría costado bastante si no hubiese leído hace tiempo el libro de Lampedusa, del que tengo un grato recuerdo, pero lo que más me extrañó fue el cambio de nombre de Tancredi a Alfonso. El resto de películas son más 
llevaderas, pero siempre con la disposición y el ánimo preparados para una experiencia que lleva su tiempo y que no se puede disfrutar con prisas. El autor era un incondicional de Mann y Proust y su estilo cinematográfico se asemeja bastante a la prosa de ambos. La prosa de Proust es densa y cargada de adjetivos y descripciones. Lo mismo se podría decir de Visconti, cinematográficamente. El refinamiento de sus películas, su obsesión por los detalles y sus manías, emulan las narraciones del escritor francés.

Lo más insólito dentro de su estilo narrativo es el empleo del zoom. No he llegado a entender muy bien esa obsesión que tiene el director por alejarse y acercarse a la acción con un recurso estético tan feo, sobre todo, siendo alguien que tiene tan presente la belleza a la hora de hacer cine. Al final, acabas por acostumbrarte pero creo que mediante travellings, las escenas serías aun más hermosas. Me gusta cómo mueve la cámara de una manera suave y natural, cediendo el protagonismo a los personajes. El movimiento del objetivo no comienza hasta que el personaje al que va a seguir empieza a moverse. Es una cámara puesta al servicio de los actores, hasta que se cansa de permanecer con ellos y decide pasearse sola para describir el resto del decorado. La escena de Muerte en Venecia donde se conocen Aschenbach y Tadzio es un ejemplo perfecto: el espectador parte de que lo que ve es lo que vería uno de los personajes, hasta que se da cuenta de que es un paseo de la cámara, que en sus primeros compases coincidía con la vista subjetiva del actor.

Mi escena favorita es de La caída de los dioses. Martin le acaba de quitar todo el poder a su madre y su padrastro, y ocupa el puesto en la cabecera de la mesa. Acaba de convertirse en el jefe de la familia y, como para asegurarse, da unos golpes sobre la superficie con la palma abierta del mismo modo que hacía su abuelo, y después su padrastro, cuando querían que les prestasen atención. Es una escena preciosa que muestra la decadencia de la familia y el cambio de un gobierno por otro, manteniendo en esencia los rasgos antiguos. Es una aceptación del poder y también una obtención de éste. 
Otras escenas grandiosas son:

- Cuando Burt Lancaster dice "Ios cuervos van en bandadas, pero las águilas vuelan en solitario" y Helmut Berger responde con una cita de la Biblia.

- La conversación entre Burt Lancaster y Alain Delon de El gatopardo, que acaba con la mítica frase de: "Todo tiene que cambiar para que todo siga igual".

- La muerte de Aschenback en la playa veneciana, con el tinte de pelo resbalándole por la frente.

- La parte final de El inocente.

\section{Bibliografía}

LIANDRAT-GUIGUES, Suzanne (1997): Luchino Visconti. Cátedra. Madrid.

RADIGALES, Jaume (2001): Luchino Visconti Muerte en Venecia. Paidós. Barcelona.

MARÍN, Francisco (1995): El cabo del miedo. El gatopardo. Libros Dirigido. Barcelona.

LAMPEDUSA, Guiuseppe Tomasi (1991): El gatopardo. Cátedra. Madrid.

RENAULT D'ALLONNES, Fabrice (2003): La luz en el cine. Cátedra. Madrid.

MANN, Thomas (1997): La montaña mágica. Edhasa. Barcelona.

PROUST, Marcel (2000): En busca del tiempo perdido. Alianza editorial. Madrid. 